\title{
Interleukin-1 $\beta$ modulates state-dependent discharge activity of preoptic area and basal forebrain neurons: role in sleep regulation
}

\author{
Md. Noor Alam, ${ }^{1,2}$ Dennis McGinty, ${ }^{1,2}$ Tariq Bashir, ${ }^{1}$ Sunil Kumar, ${ }^{1,3}$ Luca Imeri, ${ }^{4}$ Mark R. Opp ${ }^{5}$ \\ and Ronald Szymusiak ${ }^{1,3}$ \\ ${ }^{1}$ Veteran Affairs Greater Los Angeles Health Care System, 16111 Plummer Street, North Hills, CA 91343, USA \\ ${ }^{2}$ Department of Psychology, and \\ ${ }^{3}$ Department of Medicine, University of California, Los Angeles, CA 90033, USA \\ ${ }^{4}$ Institute of Human Physiology II, University of Milan, Milan, Italy \\ ${ }^{5}$ Departments of Anesthesiology and Molecular \& Integrative Physiology, University of Michigan, Ann Arbor, Ml 48109, USA
}

Keywords: cytokine, extracellular unit recording, interleukin-1 receptor antagonist, microdialysis, rat

\begin{abstract}
Interleukin-1 $\beta$ (IL-1) is a pro-inflammatory cytokine that has been implicated in the regulation of nonrapid eye movement (nonREM) sleep. IL-1, IL-1 receptors and the IL-1 receptor antagonist (ra) are present normally in discrete brain regions, including the preoptic area (POA) of the hypothalamus and the adjoining magnocellular basal forebrain (BF). The POA/BF have been implicated in the regulation of sleep-wakefulness. We hypothesized that IL-1 promotes nonREM sleep, in part by altering the state-dependent discharge activity of POA/BF neurons. We recorded the sleep-wake discharge profiles of 83 neurons in the lateral POA/BF and assessed the effects of IL-1, IL-1ra, and IL-ra + IL-1 delivered through a microdialysis probe on state-dependent neuronal discharge activity. IL-1 decreased the discharge rate of POA/BF neurons as a group $(n=55)$ but wake-related and sleep-related neurons responded differently. IL-1 significantly decreased the discharge rate of wake-related neurons. Of 24 wake-related neurons studied, $19(79 \%)$ neurons exhibited a greater than $20 \%$ change in their discharge in the presence of IL-1 during waking. IL-1 suppressed the discharge activity of 18 of 19 responsive neurons. Of 13 sleep-related neurons studied, IL-1 increased the discharge activity of five and suppressed the discharge activity of four neurons. IL-1 ra increased the discharge activity of four of nine neurons and significantly attenuated IL-1-induced effects on neuronal activity of POA/BF neurons $(n=19)$. These results suggest that the sleep-promoting effects of IL-1 may be mediated, in part, via the suppression of wake-related neurons and the activation of a subpopulation of sleeprelated neurons in the POA/BF.
\end{abstract}

\section{Introduction}

Interleukin-1 $\beta$ (IL-1) is a pro-inflammatory cytokine that plays a key role in mediating a variety of host responses to infection and inflammation, including fever and other components of the acute phase response (Rosenwasser, 1998; Rothwell \& Luheshi, 2000; Konsman et al., 2002). A growing body of evidence suggests that IL-1 is involved in the regulation of nonrapid eye movement (nonREM) sleep under both pathologic and normal physiologic conditions (Obal \& Krueger, 2003). The systemic or intracerebroventricular (ICV) administration of exogenous IL-1 promotes nonREM sleep (Krueger et al., 1984; Opp et al., 1991). By contrast, inhibition of endogenous IL-1 by the IL-1 receptor antagonist (IL-1ra) or anti IL-1 antibodies administered centrally suppresses spontaneous nonREM sleep (Opp \& Krueger, 1991; Opp \& Krueger, 1994; Takahashi et al., 1996). AntiIL-1 antibodies also inhibit the compensatory sleep rebound subsequent to sleep deprivation (Opp \& Krueger, 1994). IL-1 concentrations in cerebrospinal fluid peak at the onset of sleep (Lue et al., 1988;

Correspondence: Dr Ronald Szymusiak, ${ }^{1}$ Neurophysiology Research (151A3), as above. E-mail: rszym@ucla.edu

Received 3 February 2004, revised 19 April 2004, accepted 30 April 2004
Hohagen et al., 1993). Substances or stimuli that induce IL-1 production increase nonREM sleep, whereas substances that inhibit IL-1 action suppress nonREM sleep (Opp et al., 1988, 1989). IL-1 type 1 receptor knock-out mice spend less time in nonREM sleep than do wild-type control mice (Fang et al., 1998). Exposure to infectious challenges induces nonREM sleep in animals (Toth \& Krueger, 1988, 1989). Despite numerous findings supporting a role of IL-1 in sleep regulation, the brain structures, the neuronal pathways and the neuronal types that mediate IL-1-induced nonREM sleep are poorly understood.

The preoptic area (POA) of the hypothalamus plays a key role in multiple physiologic functions, including the regulation of sleepwakefulness (Saper et al., 2001; McGinty \& Szymusiak, 2003). Lesions, or reversible inactivation of POA, produce arousal whereas stimulation of this area produces sleep (Alam \& Mallick, 1990; McGinty et al., 1994; Lu et al., 2000; McGinty \& Szymusiak, 2003). The POA contains sleep-related neurons, i.e. neurons that are activated at nonREM sleep onset (Sherin et al., 1996; Szymusiak et al., 1998). The adjoining magnocellular basal forebrain (BF) is critically involved in electroencephalogram (EEG) activation and behavioral arousal (Szymusiak et al., 2000; Jones, 2004; Semba, 2004). The BF contains 
a predominant population of wake-related neurons (Alam et al., 1999; Detari et al., 1999). The physiologic process of nonREM sleep onset is hypothesized to involve the activation of sleep-related neurons and inhibition of wake-related neurons.

Various in vivo as well as in vitro studies suggest that $\mathrm{POA} / \mathrm{BF}$ is one of the potential sites that mediates IL-1 induced physiologic effects (Nakashima et al., 1989; Oka et al., 1995; Xi \& Toth, 2000). We hypothesized that the sleep-promoting effects of IL-1 are mediated via the suppression of wake-related neurons and/or the activation of sleep-related neurons in the POA/BF. In this study we determined the effects of IL-1 delivered locally through a microdialysis probe on the extracellular discharge activity of recorded POA/BF neurons during waking and nonREM sleep. We further determined if the effects of IL-1 on POA/BF neurons were mediated via IL-1 receptors.

\section{Materials and methods}

\section{Experimental subjects and surgical procedures}

Experiments were performed on nine Sprague-Dawley male rats, weighing between 250 and $350 \mathrm{~g}$. These rats were maintained on 12 : 12-h light-dark cycle (lights on at $08.00 \mathrm{~h}$ ) and with food and water continuously available. All experiments were conducted in accordance with the National Research Council Guide for the Care and Use of Laboratory Animals and were approved by Institutional Animal Research Committee. Under surgical anesthesia (ketamine + xylazine, $80: 10 \mathrm{mg} / \mathrm{kg}$, i.p.) and aseptic conditions, rats were stereotaxically prepared for chronic recording of EEG and electromyogram (EMG) signals, POA/BF neuronal activity, and microdialysis delivery of drugs adjacent to the recording site. The details of the surgical procedure and experimental protocol have been described previously (Alam et al., 1999). In brief, EEG and EMG electrodes were implanted according to standard technique (Alam \& Mallick, 1990). A single-barrel mechanical microdrive was implanted such that its tip rested $3 \mathrm{~mm}$ above the dorsal aspect of the POA/BF (A, -0.2 to -0.5; L, 1.4-1.8; H, 4.5-5.5; Paxinos \& Watson, 1998). Five pairs of microwires, each consisting of two $20-\mu \mathrm{m}$ insulated stainless steel wires glued together except for $2.0 \mathrm{~mm}$ at the tip, were passed through the barrel such that their tips projected into POA/BF. A microdialysis guide cannula was implanted $0.3-0.5 \mathrm{~mm}$ lateral to the microdrive and blocked with a stylet.

\section{Substances}

IL-1 $\beta$ (recombinant rat IL-1 $\beta$ expressed in Escherichia coli) and the IL-1 ra (recombinant human IL-1ra expressed in E. coli) were purchased from $\mathrm{R}$ \& $\mathrm{D}$ Systems, Inc. (Minneapolis, USA). Lyophilized substances were reconstituted in pyrogen-free artificial cerebrospinal fluid (aCSF; composition in $\mathrm{mM}, 145 \mathrm{Na}^{+}, 2.7 \mathrm{~K}^{+}$, $1.0 \mathrm{Mg}^{2+}, 1.2 \mathrm{Ca}^{2+}, 1.5 \mathrm{Cl}^{-}, \mathrm{pH}, 7.2$ ) containing $0.1 \%$ bovine serum albumin, aliquoted and stored at $-20{ }^{\circ} \mathrm{C}$. Immediately prior to use, substances were brought to appropriate concentrations by adding aCSF. Each aliquot was used only once.

\section{Data acquisition}

Experiments were started at least 10 days after surgery. All experiments were conducted on unanesthetized and freely behaving animals during lights-on period. At least $12 \mathrm{~h}$ before the beginning of the recording sessions, the stylet of the microdialysis guide cannula was replaced by a microdialysis probe (EICOM, Japan; A-I model; material, regenerated cellulose; semipermeable membrane length, $1 \mathrm{~mm}$; outer diameter, $0.22 \mathrm{~mm}$; molecular cut-off, $50 \mathrm{kDa}$ ). The length of the probe was set such that the extracellular environment of the recorded neurons was within the estimated dialysis area of the semipermeable membrane. The microdialysis probe was fixed and microwires were advanced adjacent to the side of the exposed microdialysis membrane to minimize the tissue trauma and to ensure maximum stability of the unit recording. The time taken by the solution to travel from the reservoir to the tip of the probe was 15$16 \mathrm{~min}$.

The microdrive was advanced in $25-30-\mu \mathrm{m}$ steps until action potential signals with signal-to-noise ratio $\geq 2.0$ were found. Individual action potentials were sorted from amplified raw signals using Spike 2 software (Cambridge Electronic Design 1401, London, UK). EEG, EMG and raw microwire signals were digitized and stored on a disk for subsequent off-line analyses.

The baseline discharge rate of isolated POA/BF neurons was recorded through $2-3$ stable sleep-wake cycles $(\sim 30-45 \mathrm{~min})$ with pyrogen-free aCSF. After baseline recordings, $20-25 \mu \mathrm{L}$ of aCSF containing 40-50 ng IL-1 or $20 \mu \mathrm{L}$ aCSF containing $2 \mu \mathrm{g}$ IL-1ra was perfused through a microdialysis membrane adjacent to the recorded neurons for 10-12 min. The in vitro recovery of the probe for IL-1 (molecular weight, $17 \mathrm{kDa}$ ), as determined by radio-immunoassay, was in the range $4-5 \%$. Therefore, the amount of IL-1 delivered into the $\mathrm{POA} / \mathrm{BF}$ was estimated to be $2-2.5 \mathrm{ng}$, a concentration similar to the lower dose used in earlier studies (Opp et al., 1991). The in vitro recovery of IL-ra was not determined. However, given the higher molecular weight of IL-1ra (25 kDa), its delivery was estimated to be lower than that of IL-1. The concentration of IL-1ra used in this study was based on previous findings that a 1000-10 000-fold excess of IL-ra was required to block the effects of IL-1 (Dripps et al., 1991; Opp $\&$ Krueger, 1991). This study was aimed at investigating the acute effects of IL-1 or IL-1 ra on the state-dependent discharge activity of the $\mathrm{POA} / \mathrm{BF}$ neurons without triggering strong behavioral responses. Therefore, the substances were dialysed locally into POA/BF for a short duration and doses adjusted to detect responses of neurons without changing behavioral state. To determine if IL-1-induced changes on POA/BF neuronal discharge were IL-1 receptor mediated, a subset of neurons was examined for the effects of IL-1 in the presence of IL-1ra. In those cases, IL-1 was microdialysed immediately after IL-1ra. After delivery of substances, the perfusion solution was switched back to aCSF and the recording continued for another 45-90 min or until the discharge rate returned back to the baseline levels as wash out or recovery. During the entire recording session, rats were undisturbed except, if necessary, a stable episode of waking for 2-3 min was achieved by mild auditory stimuli or gentle touch.

At the end of the recording session, under deep anesthesia $(100 \mathrm{mg} / \mathrm{kg}$, i.p., pentobarbital) rats were perfused transcardially with $0.1 \mathrm{M}$ phosphate buffer followed by $4 \%$ paraformaldehyde and $10 \%$ and $30 \%$ sucrose in phosphate buffer. Brains were removed and equilibrated in $30 \%$ sucrose and then freeze-sectioned at $40 \mu \mathrm{m}$ thickness. The location of the microdialysis probe and the microwire tracts were histologically identified in Nissl-stained sections. The anatomical distribution of the recorded neurons and their sleep-wake discharge profiles were plotted (Fig. 1).

\section{Data analysis}

Sleep-wake states were identified on the basis of EEG and EMG patterns using standard criteria (Alam \& Mallick, 1990). The baseline mean discharge rate was calculated from 40- to 300-s blocks of 
A
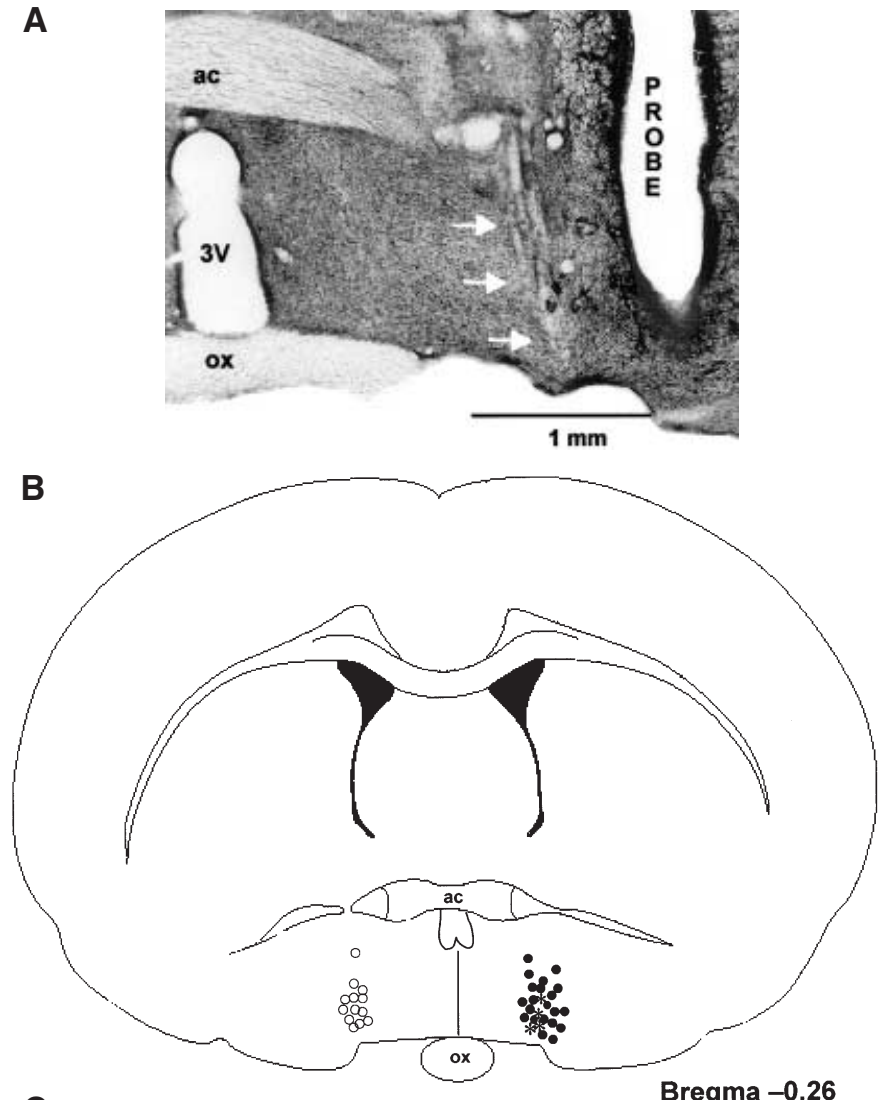

C

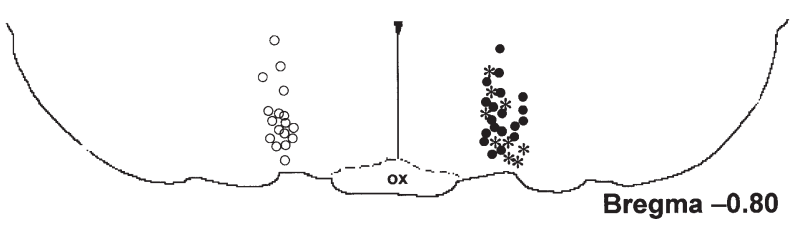

FIG. 1. Anatomical localization and discharge profiles of the recorded neurons. (A). Photomicrograph of a histological section through POA/BF showing locations of microwire tracks (arrows) and the track of the microdialysis probe. (B and C) Line drawings of the two representative brain sections at two rostrocaudal planes showing the distribution of the recorded neurons. The neuronal recordings were made unilaterally. However, wakerelated neurons and sleep-related neurons have been shown on the right-hand side and state-indifferent neurons have been shown on the left-hand side of the drawings for better visualization. Filled circles, wake-related neurons; open circles, state-indifferent neurons; *, sleep-related neurons; ac, anterior commissure; ox, optic chiasm; 3V, third ventricle.

stable waking and nonREM sleep during 3-5 spontaneous waking and nonREM sleep episodes. The discharge rates of neurons during waking and nonREM sleep in the presence of drugs were determined by comparing discharge rates during all episodes of waking and nonREM sleep occurring during the first 20-40 min of drug delivery. In an earlier study we found that adenosinergic agents produced their effects within 1-5 min after their arrival into the extracellular space (Alam et al., 1999). Therefore, effects of IL-1 and/or IL-1ra were determined after $5 \mathrm{~min}$ of their expected arrival into the extracellular environment of the recorded neurons. The effects of drugs usually lasted from 20 to $45 \mathrm{~min}$. In some cases, effects of IL-1 lasted for more than $60 \mathrm{~min}$. Because drugs were perfused for a short duration, and REM sleep was usually not observed during drug treatments, only waking and nonREM sleep-related discharge rates were analysed.
The sleep-wake discharge profiles of neurons were determined by criteria adopted previously (Alam et al., 1995; Szymusiak et al., 1998). Neurons were defined as wake-related if the ratio of their discharge rates during nonREM sleep and waking (nonREM/wake) was $\leq 0.75$. Neurons were classified as sleep-related if the non$\mathrm{REM} /$ wake ratio was $\geq 1.25$. Neurons having a nonREM/wake ratio of $>0.75$ and $<1.25$ were considered as state-indifferent neurons. Neurons were considered responsive to drugs if they exhibited a change in discharge rate that was greater than $20 \%$ of the baseline discharge rate. Neurons discharging less than one spike per second were not considered for analysis.

The Wilcoxon matched-pairs signed rank test was used to determine the statistical significance of the IL-1, IL-ra or IL-1ra + IL-1 treatments on the neuronal discharge activity during waking and nonREM sleep. The Mann-Whitney rank sum test was used to determine the statistical significance of the difference between IL-1 treatment alone and IL-ra + IL-1 treatments conducted on two different groups of neurons.

\section{Results}

During aCSF perfusion neuronal recordings exhibited stable signal-tonoise ratio and sleep-wake-related discharge patterns typical of POA/BF neurons (Szymusiak et al., 1998; Alam et al., 1999; Detari et al., 1999). The microdialytic perfusion of IL-1, IL-1ra, or IL-1ra followed by IL-1 consistently affected POA/BF neuronal discharge. Computer-generated templates, based upon spike shape parameters used for spike sorting, eliminated possible artifactual spikes and documented the activity of the same neuron across baseline, drug delivery and washout conditions (see Figs 2 and 3).

\section{Locations of the recorded neurons}

A photomicrograph of representative microwire tracks adjacent to a microdialysis probe and the anatomical distribution of all recorded neurons coded with their sleep-wake discharge profiles are shown in Fig. 1. The majority of recorded neurons were localized in the lateral POA, including dorsolateral and ventrolateral POA. Additional recording sites included adjoining caudal portions of the horizontal limb of the diagonal band of Broca, the substantia innominata and medial aspects of the magnocellular preoptic nucleus in the BF.

\section{Effects of IL-1 on POA/BF neurons}

The effect of IL-1 was studied on 55 POA/BF neurons. IL-1 decreased the mean $( \pm$ SEM) discharge rate of POA/BF neurons as a group, irrespective of their sleep-wake discharge profiles, during waking $(5.39 \pm 0.67$ vs. $3.98 \pm 0.73, P<0.001)$ and nonREM sleep ( $4.85 \pm 0.79$ vs. $4.1 \pm 0.80, P<0.01)$. However, discharge profiles of wake- and sleep-related neurons were differentially affected by IL-1.

\section{Effects of IL-1 on wake-related neurons}

The effects of IL-1 on the discharge rate of an individual wake-related neuron across the sleep-wake cycle and on the mean discharge rate of wake-related neurons as a group $(n=24)$ during waking and nonREM sleep are shown in Figs 2 and 4, respectively. The mean discharge rate of these neurons during baseline waking was $65 \%$ higher than their mean discharge rate during baseline nonREM sleep (mean nonREM/wake ratio, $0.35 \pm 0.04$ ). The discharge rate of wakerelated neurons as a group was significantly reduced by IL-1 during 

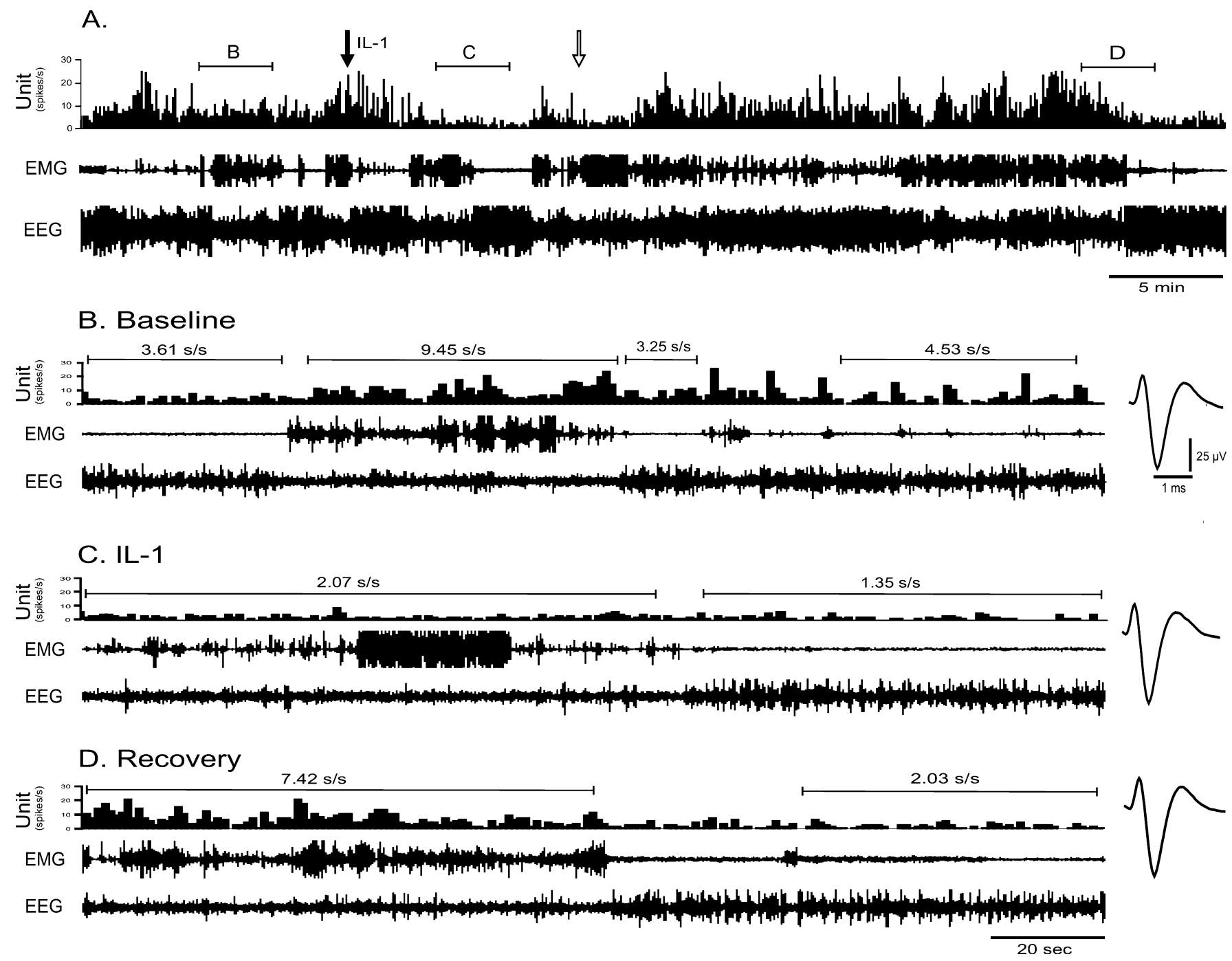

FIG. 2. Effects of IL-1 on an individual wake-related neuron. (A) A 52-min continuous recording showing the discharge rate of an individual wake-related neuron during baseline, in the presence of IL-1 and during washout. Filled and blank arrows indicate arrival of IL-1 at the microdialysis probe and the beginning of IL-1 washout, respectively. IL-1 was perfused for $12 \mathrm{~min}$. Panels B-D are expanded tracings of the marked areas in A, showing wake- and sleep-related neuronal discharge during baseline (B), during IL-1 perfusion (C) and after washout (D). The action potentials on the side panels represent the average waveforms of all the action potentials recorded during the representative sections in each condition. The numbers represent discharge rates (spikes per second) during the marked sections of the recording period. EEG, electroencephalogram; EMG, electromyogram.

both waking $(-47 \pm 8 \%$, range -96 to $134 \%, P=0.001)$ and nonREM sleep $(-28 \pm 13 \%$, range -99 to $163 \%, P=0.031$; Fig. 4). The IL-1-induced suppression in the discharge during waking was significantly higher than that induced during nonREM sleep $(-47 \pm 8 \%$ vs. $-28 \pm 11, P=0.0024)$.

Individually, 19 of 24 (79\%) wake-related neurons exhibited a greater than $20 \%$ change in response to IL-1 during waking. Of 19 responsive neurons, 18 exhibited decreased discharge in the presence of IL-1 during waking. During nonREM sleep, however, only nine of these 18 neurons exhibited decreased discharge of greater than $20 \%$ in response to IL-1. One neuron exhibited increased discharge during both waking and nonREM sleep. One neuron, which was not responsive to IL-1 during waking, exhibited increased discharge during nonREM sleep.

\section{Effects of IL-1 on sleep-related neurons}

The effects of IL-1 on the discharge rate of an individual sleep-related neuron and on the mean discharge rate of sleep-related neurons as a group $(n=13)$ during waking and nonREM sleep are shown in Figs 3 and 4 , respectively. These neurons as a group exhibited $163 \%$ higher discharge during baseline nonREM sleep as compared with baseline waking (mean nonREM/wake ratio, $2.63 \pm 0.54$ ).

Nine of 13 sleep-related neurons $(69 \%)$ responded to IL-1 perfusion during waking. Of responsive neurons, five exhibited increased discharge $(199 \pm 102 \%)$ and four exhibited decreased discharge $(-57 \pm 10 \%)$ in the presence of IL-1 during waking. During nonREM sleep, these neurons exhibited similar response profiles, except for one neuron that exhibited increased discharge during waking which showed a decreased discharge. IL-1 did not alter the discharge rate of sleep-related neurons as a group during waking $(76 \pm 51 \%$, range 602 to $-81 \%, P=0.893)$ or during nonREM sleep $(24 \pm 32 \%$, range 250 to $-73 \%, P=0.789$; Fig. 4$)$.

\section{Effects of IL-1 on state-indifferent neurons}

Eighteen of the neurons recorded in the $\mathrm{POA} / \mathrm{BF}$ were stateindifferent. These neurons had a mean nonREM/wake discharge ratio of $0.92 \pm 0.04$. IL-1 decreased the activity of state-indifferent neurons without inducing any differential effects during waking 

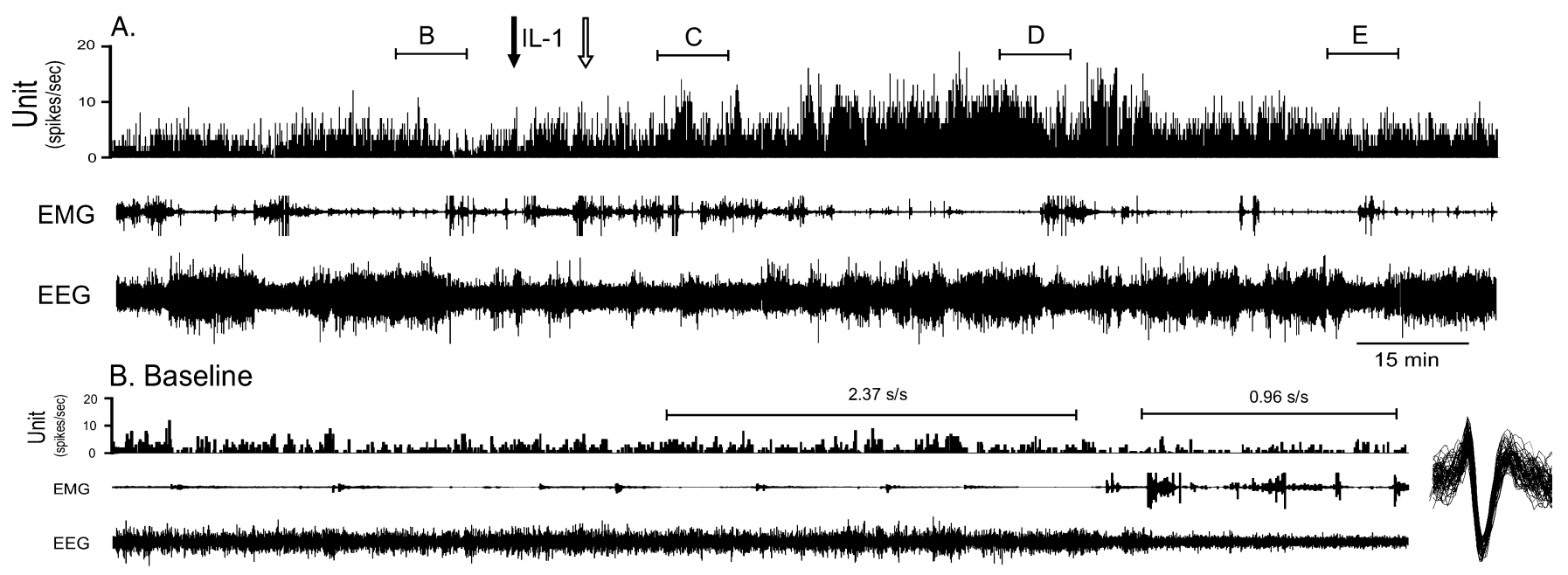

C. IL-1 $5.39 \mathrm{~s} / \mathrm{s}$

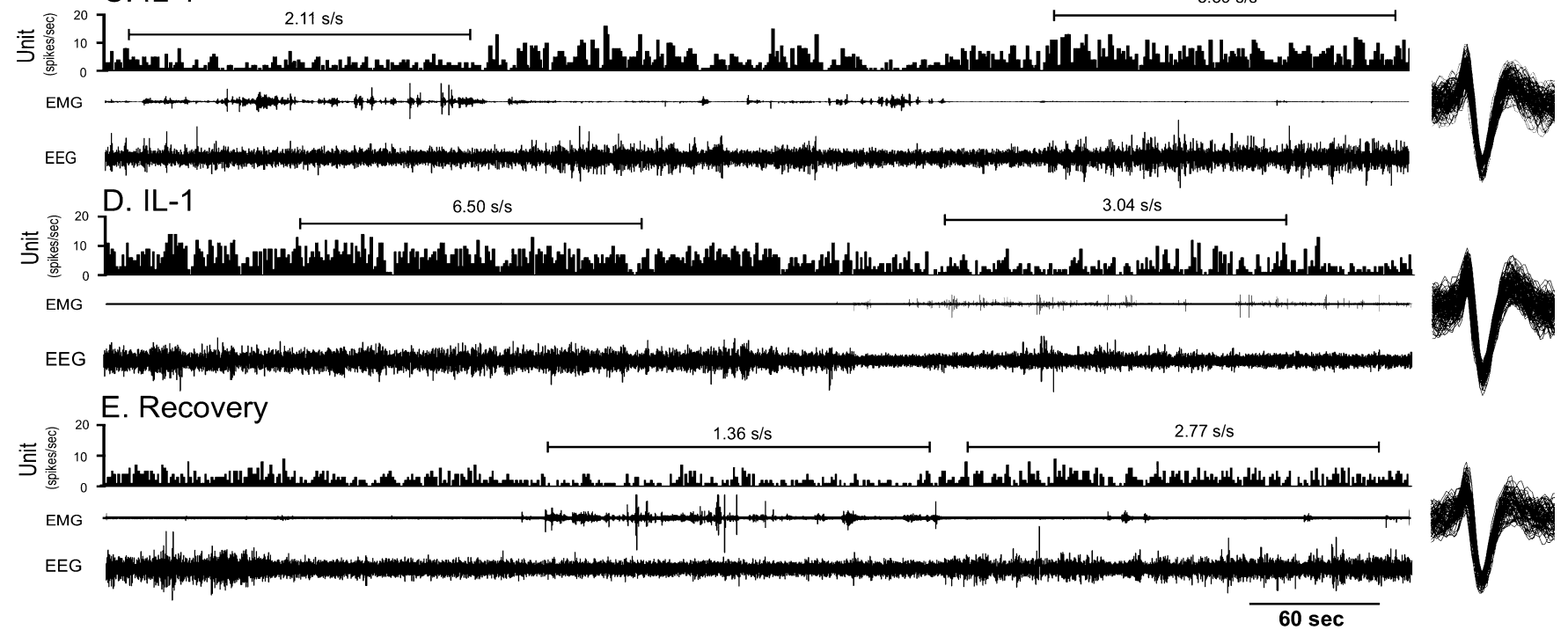

FIG. 3. Effects of IL-1 on an individual sleep-related neuron. (A) A 174-min continuous recording showing the discharge rate of an individual sleep-related neuron during baseline, in the presence of IL-1 and after washout. Panels B-E are 10-min expanded tracings of the marked areas in A. IL-1 induced increased discharge during both waking and nonREM sleep in this neuron (onset of effect and the maximum effects are shown in C and D, respectively). The effect of IL-1 persisted after washout but eventually the discharge rate returned to baseline levels (E). The action potentials on the side panels are the actual spikes captured during $20 \mathrm{~s}$ of the representative sections in each condition. An increase in the number of spikes without any change in spikes can be seen. Other details are as described in the legend to Fig. 2.

$(-33 \pm 7 \%$, range -90 to $47 \%)$ or nonREM sleep $(-29 \pm 10 \%$, range -96 to $66 \%$, Fig. 4). Of 18 state-indifferent neurons examined, 12 (67\%) were responsive to IL-1 during waking, including eleven that exhibited decreased and one that exhibited increased discharge. During nonREM sleep, all neurons remained responsive except for two that exhibited increased discharge.

\section{Effects of IL-1ra on POA/BF neurons}

The effect of IL-1ra was examined on the discharge activity of nine neurons, four wake-related and five state-indifferent (Figs 5 and 6). Five of nine neurons (56\%) responded to IL-1 ra perfusion during waking, including four that exhibited increased (two wake-related and two state-indifferent) and one (wake-related) that exhibited decreased discharge. During nonREM sleep, one neuron that was not responsive during waking exhibited increased discharge. IL-1 ra slightly increased the discharge rate of POA/BF neurons as a group, which was not significant during both waking $(15 \pm 11 \%$, range -27 to $86 \%$,
$P=0.865)$ and nonREM sleep $(42 \pm 20 \%$, range -13 to $126 \%$, $P=0.612)$.

\section{Effects of IL-1 in the presence of IL-1ra on POA/BF neurons}

The effect of IL-1ra + IL-1 was examined on the discharge activity of 19 neurons, 12 wake-related and seven state-indifferent. Seven of these 19 neurons (37\%; five wake-related and two state-indifferent) responded by exhibiting suppressed discharge in response to IL-1 ra + IL-1 during waking.

The effects of IL-1ra + IL-1 on the discharge of an individual wakerelated neuron across the sleep-wake cycle and on the mean discharge rate of wake-related neurons as a group during waking and nonREM sleep are shown in Figs 7 and 8, respectively. Only five of 12 wakerelated neurons $(42 \%)$ responded to IL-1ra + IL-1, whereas the same dose of IL-1 in the absence of IL-ra suppressed the activity of $75 \%$ of wake-related neurons (see Fig. 4A). Wake-related neurons as a group exhibited suppressed discharge in the presence of IL-1ra + IL-1 


\section{A. Wake-related neurons}

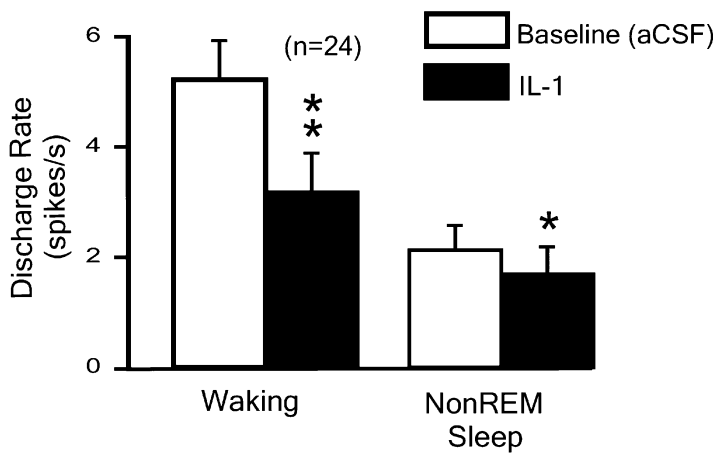

B. Sleep-related neurons

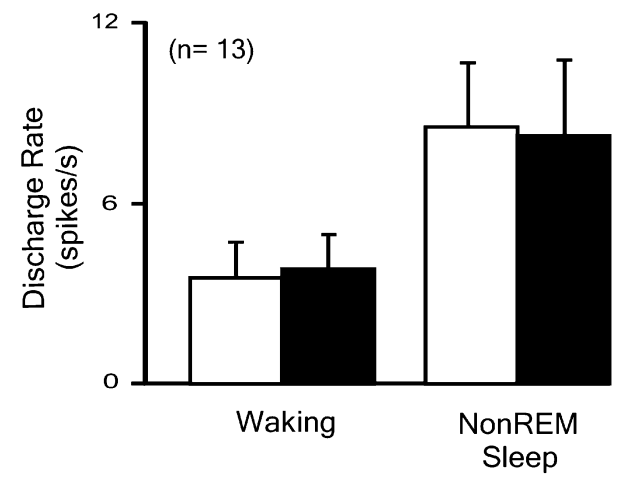

C. State-indifferent neurons

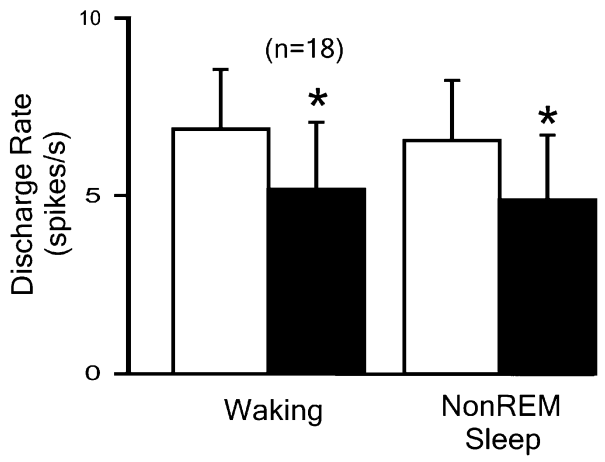

FIG. 4. Effects of IL-1 on the mean discharge activity of POA/BF neurons. Effects of IL-1 on the mean discharge rate $( \pm$ SEM) of wake-related neurons (A), sleep-related neurons (B) and state-indifferent neurons (C) during waking and nonREM sleep. IL-1 suppressed the discharge rate of wake-related and state-indifferent neurons. IL-1 produced no significant changes on the discharge activity of sleep-related neurons as a group. ${ }^{* *} P<0.01 ;{ }^{*} P<0.05$ (Wilcoxon matched-pairs signed rank test).

during waking $(-19 \pm 4 \%$, range -45 to $2 \%$ ). However, this effect was significantly weaker than that produced by IL-1 alone (Fig. 8). IL-ra + IL-1 produced no significant changes in the mean discharge of $\mathrm{POA} / \mathrm{BF}$ neurons as a group during waking $(-14 \pm 4 \%$, range -45 to $18 \%, P=0.091)$ and nonREM sleep $(3 \pm 7 \%$, range -30 to $78 \%$, $P=0.623)$.

\section{Discussion}

The present study demonstrates that IL-1 microdialysed locally into POA/BF suppresses the activity of the majority (75\%) of recorded wake-related neurons in unanesthetized freely behaving animals. Although the effects of IL-1 on sleep-related neurons in this brain region are more variable, $39 \%$ of all recorded sleep-related neurons exhibited increased discharge rates in the presence of this cytokine. The IL-1-induced suppression of POA/BF wake-related neurons was attenuated by specific IL-1 receptor blockade. Collectively, these results suggest that IL-1 may promote nonREM sleep by inhibiting wake-related neurons and activating at least a subpopulation of sleeprelated neurons in the POA/BF. That the effects of IL-1 on the discharge activity of $\mathrm{POA} / \mathrm{BF}$ neurons are specific is supported by the following evidence: (i) the activity of the same neuron was recorded across baseline, drug delivery and washout conditions as ensured by digital spike sorting; (ii) for each individual neuron the effects of IL-1 were consistent, reversible and time-linked to the duration of administration; and (iii) the effect of IL-1 was partially blocked by IL-ra, although IL-1ra alone at the single given dose had little effect on the spontaneous discharge rate.

Multiple lines of evidence support a hypothesis that endogenous IL-1 is involved in sleep regulation (Obal et al., 1990; Opp \& Krueger, 1991, 1994; Obal \& Krueger, 2003). This is the first study, to our knowledge, that has examined the effects of locally delivered IL-1 on the discharge activity of behaviorally identified POA/BF neurons during spontaneous waking and sleep. It is well documented that POA/BF neurons play critical roles in the regulation of sleep and behavioral arousal (Alam et al., 1995; Szymusiak et al., 1998, 2000; Detari et al., 1999; McGinty \& Szymusiak, 2003; Jones, 2004; Semba, 2004). We recorded neurons in the lateral preoptic area, with additional recording sites in the adjacent horizontal limb of the diagonal bands of Broca and the medial aspects of the magnocellular preoptic nucleus and substantia innominata. These latter areas contain cholinergic neurons that are critically involved in behavioral arousal and neocortical activation (Szymusiak et al., 2000; Jones, 2004; Semba, 2004). We can hypothesize that some of the wake-related neurons that were inhibited by IL-1 in the present study may have been cholinergic. However, the regions from which we recorded also contain noncholinergic wake-related neurons, and the extent to which IL-1 targets cholinergic vs. noncholinergic arousal systems remains to be determined.

IL-1 administered ICV into rats increases nonREM sleep across an effective dose range of about 2.5-10 ng (Opp et al., 1991; Gemma et al., 1997; Imeri et al., 1999). Concentrations of IL-1 greater than $10 \mathrm{ng}$ (e.g. $25 \mathrm{ng}$ ) when injected ICV disrupt nonREM sleep and promote arousal (Opp et al., 1991; Gemma et al., 1997). In addition, the same dose of IL-1 may differentially affect sleep-wake behavior depending upon the circadian time of its administration. For example, $10 \mathrm{ng}$ of IL-1 administered ICV prior to the dark phase promotes nonREM sleep, whereas this dose promotes wakefulness when given prior to the light phase (Opp et al., 1991). The present study was conducted during the light phase and a low concentration of IL-1 was perfused to determine the acute response of the POA/BF neurons. A predominant suppression of wake-related neurons and activation of a subset of sleep-related neurons by IL-1 as found in this study may be the mechanism whereby nonREM sleep is promoted by IL-1. It is possible that these neuronal populations would respond differently to higher doses of IL-1.

The specific brain areas and pathways that mediate the nonREM sleep-promoting effects of IL-1 remain poorly understood. However, our study in conjunction with earlier studies suggests that IL-1 promotes nonREM sleep in part by acting on multiple arousal systems and in part by inhibiting wake-related neurons. We recently demonstrated that IL-1 may inhibit wake-promoting monoaminergic systems in dorsal raphe and locus coeruleus (Manfridi et al., 2003). IL-1, when 
A. Baseline (aCSF)
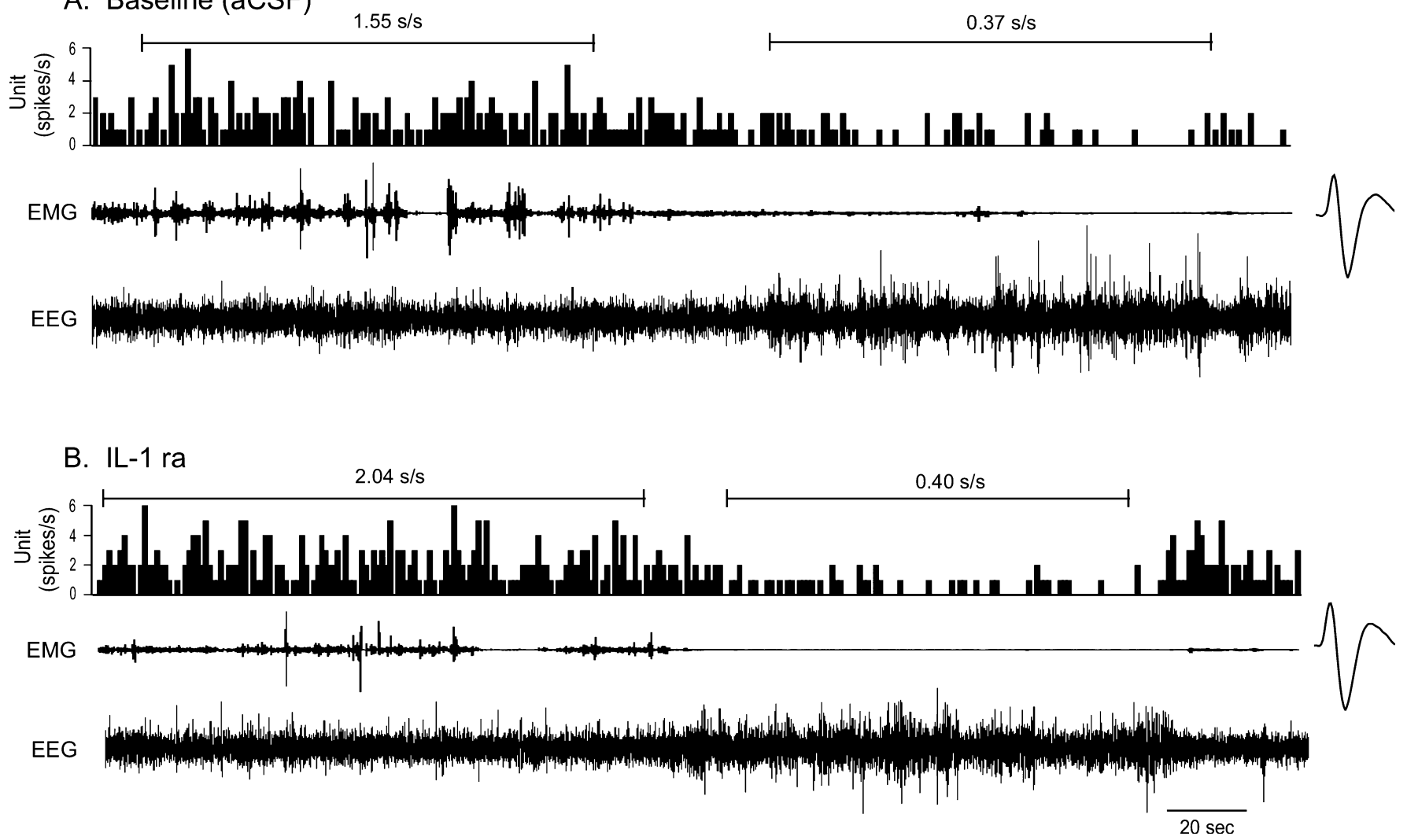

FIG. 5. Effects of IL-1ra on the discharge activity of an individual wake-related neuron. Five-minute continuous recording showing the sleep- and wake-related discharge activity of an individual wake-related neuron during baseline (A) and during IL-1ra perfusion (B). In response to IL-1ra, this neuron exhibited slightly elevated discharge. The abbreviations and details as described in the legend to Fig. 2.

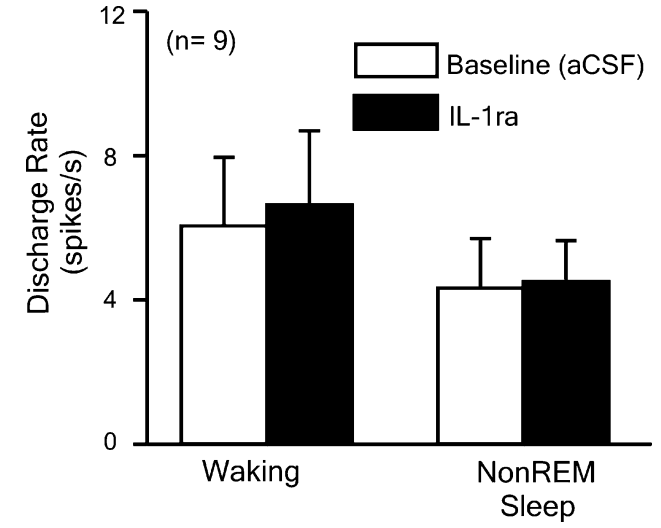

FIG. 6. Effects of IL-1ra on the mean discharge rate $( \pm$ SEM) of POA/BF neurons during waking and during nonREM sleep. IL-1ra did not affect the mean discharge of neurons during waking or during nonREM sleep.

microinjected into the dorsal raphe of freely behaving rats, induces nonREM sleep. In addition, we found in vitro that application of IL-1 suppresses the spontaneous discharge activity of physiologically and pharmacologically identified serotonergic dorsal raphe neurons (Manfridi et al., 2003). Finally, low doses of IL-1 microinjected into locus coeruleus suppress neuronal activity, whereas higher doses increase locus coeruleus neuronal activity, effects that are blocked by IL-1ra (Borsody \& Weiss, 2002). The strong suppression of discharge rates of wake-related neurons in the present study is consistent with the results of these previously published reports.
Sleep-related neurons have been identified in the ventrolateral POA by c-Fos protein immunohistochemistry and unit recording studies (Sherin et al., 1996; Szymusiak et al., 1998). Neurons in the ventrolateral POA that express fos protein immunoreactivity during sleep co-localize with galanin and GABA (Gaus et al., 2002; Gong et al., 2004). In the present study, five of 13 sleep-related neurons were recorded within and just dorsal to the ventrolateral POA and three of these neurons were activated by IL-1. Although a limited number of neurons were recorded in this region, these results suggest that sleeprelated neurons in the ventrolateral POA may in part mediate the nonREM sleep-promoting effects of IL-1. This conclusion is consistent with a recent study showing increased Fos-immunoreactivity in ventrolateral POA neurons after bolus ICV administration of IL-1, during which time these animals slept more than their respective controls (Baker et al., 2003).

We found that IL-ra attenuates IL-1-induced suppression of the discharge of wake-related neurons. These results suggest that IL-1induced suppression of wake-related neurons is receptor-mediated and specific. These data complement and confirm earlier in vitro and in vivo studies. For example, in vitro IL-ra blocks IL-1-induced inhibition of thermosensitive neurons in the POA (Xin \& Blatteis, 1992). In vivo, IL-1ra attenuates the hyperalgesia produced by microinjection of IL-1 into the POA (Oka et al., 1995). ICV administration of IL-1ra blocks IL-1-induced nonREM sleep and fever (Opp \& Krueger, 1991). Under the conditions of the present study, IL-1ra significantly attenuates, but does not completely block, IL-1-induced effects on POA/BF neuronal activity of wake-related neurons. In contrast to receptors for classical neurotransmitters, cells 

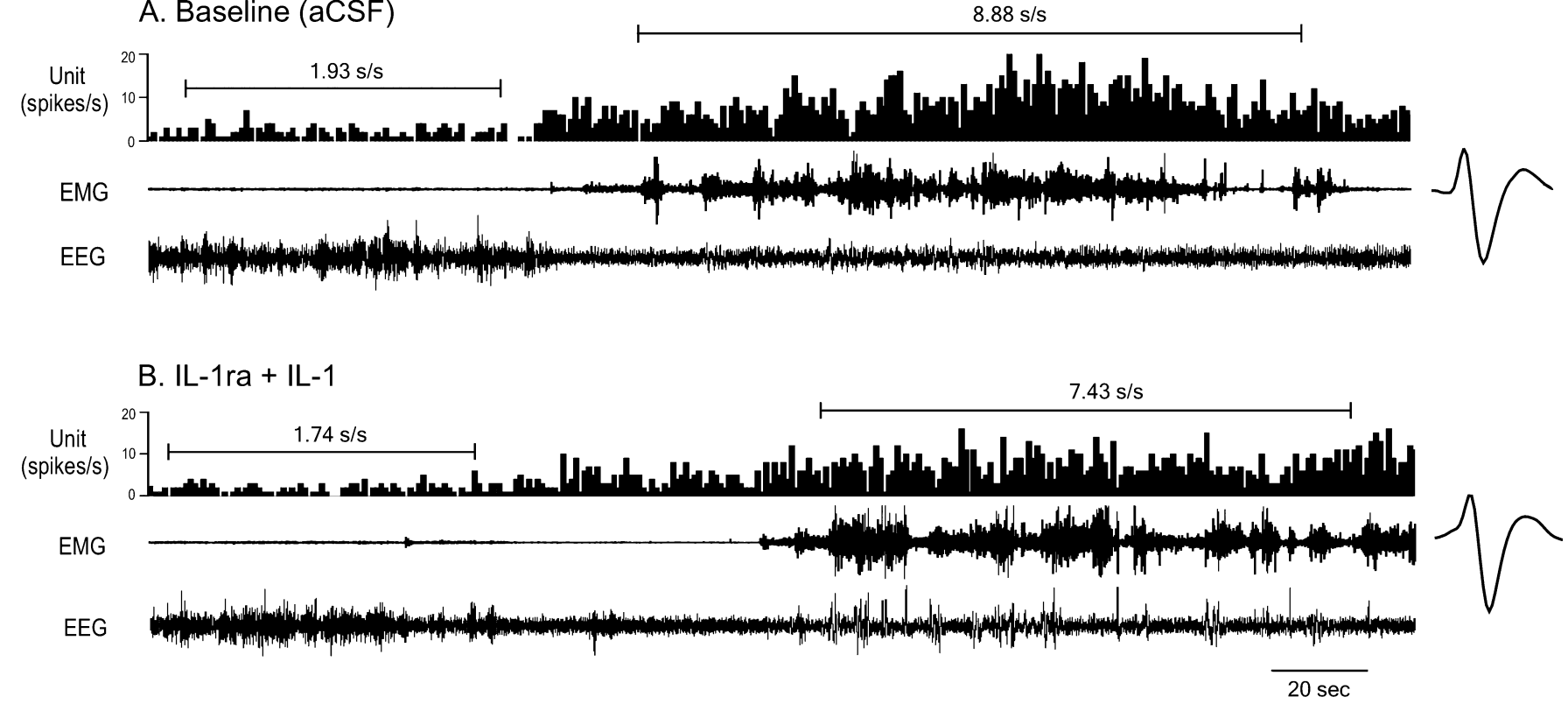

FIG. 7. Effects of IL-1 in the presence of IL-ra on the discharge rate of an individual POA/BF neuron. Continuous tracings showing wake- and sleep-related discharge activity of an individual wake-related neuron in POA/BF during baseline (A) and during IL-1 ra + IL-1 perfusion (B). In the presence of IL-1 ra, IL-1 failed to suppress the discharge of this neuron. Abbreviations and other details are as in the legend to Fig. 2.

taken from fresh tissue or circulating blood express few IL-1 receptors per cell (Dinarello, 1991; Rothwell \& Luheshi, 2000). Although transfected cells may contain up to 5000 receptors, primary cells often contain 50-200 receptors (Shirakawa et al., 1989; Dinarello, 1996). Not only are there few IL-1 receptors per cell, but only about $5 \%$ of IL-1 receptors need to be occupied before second messenger systems are activated (Gallis et al., 1989; Stylianou et al., 1992). As such, essentially all IL-1 receptors must be blocked by the IL-1ra before the biologic actions of IL-1 are completely abolished. Because of these aspects of IL-1 biology, it is often necessary to use many fold excess of IL-1ra to block IL-1 effects. For example, a 1000-fold excess of IL-1ra is required to inhibit $50 \%$ of protein kinase activation in fibroblasts in vitro (Dripps et al., 1991), and our previous studies indicate that $100 \mu \mathrm{g}$ IL-1ra is sufficient to block in vivo sleep and fever responses of rabbits to 10 ng IL-1, a 10 000-fold excess of IL-1ra to IL-1 (Opp \& Krueger, 1991). Therefore, it is possible that in the present study the dose of IL-1 ra used (100 ng) was too small to block IL-1 effects on neuronal discharge completely. Furthermore, the half-life of the IL-1ra in cerebrospinal fluid is relatively short, about 10-15 min. The fact that five wake-related neurons were responsive to IL-1 after perfusion of the IL-1ra may also be due to the short half-life of the IL-1 ra relative to the duration of IL-1 perfusion that followed. Nevertheless, it is clear that selectively and specifically antagonizing receptors before perfusion of IL-1 alters the discharge rates of wake-related neurons in a manner consistent with the hypothesis that promotion of nonREM sleep by IL-1 may result from actions on these neurons.

Because central administration of IL-ra transiently reduces spontaneous nonREM sleep in rats (Opp \& Krueger, 1991), one might hypothesize that IL-ra itself should alter the spontaneous activity of POA/BF neurons. The aim of the present study was to demonstrate specificity for IL-1 effects on neuronal activity. Therefore, most neurons were examined for the effects of IL-1 in the presence of IL-ra and fewer neurons were recorded during perfusion of IL-ra alone. However, although a low dose of IL-1ra was used in this study, two of four wake-related neurons exhibited increased discharge in the presence of IL-ra. Although additional studies are required to elucidate fully the impact of IL-1 on these neurons, these intriguing data suggest that endogenous IL-1 may exert tonic inhibitory influences on wakerelated neurons.

The effects of IL-1 on various behaviorally identified POA/BF neurons, as described here, could be the result of direct postsynaptic effects, presynaptic effects or a combination of both. Some evidence suggests that the inhibitory effects of IL-1 on wake-related neurons may be mediated by an adenosine-dependent mechanism. Both IL-1 protein and receptors and $A_{1}$ receptors are expressed in several brain regions, including the hypothalamus (Cunningham et al., 1992; Schobitz et al., 1994; Yabuuchi et al., 1994; Ericsson et al., 1995; Ribeiro, 1999; Muller, 2001). Adenosine has been implicated in the homeostatic regulation of sleep (Porkka-Heiskanen et al., 2002) and we have previously demonstrated that $\mathrm{A}_{1}$ receptor-mediated adenosinergic inhibition is involved in the suppression of $\mathrm{BF}$ neuronal activity (Alam et al., 1999). In an in vitro hippocampal slice preparation, IL-1 decreases glutamatergic excitatory postsynaptic potentials, an effect blocked by an adenosine $\mathrm{A}_{1}$ receptor antagonist (Luk et al., 1999). Endogenous glutamate plays an important role in regulating the excitability of the $\mathrm{BF}$ arousal system; local $\mathrm{BF}$ perfusion with glutamate antagonists prevents the increase in the neocortical acetylcholine release evoked by brainstem stimulation (Rasmusson et al., 1994). Although experiments to test this hypothesis directly have not been conducted, suppression of discharge in POA/BF wake-related neurons evoked by IL-1 may result, in part, from adenosinergic presynaptic modulation of glutamate release. The hypothesis that adenosinergic mechanisms are involved in mediating IL-1-induced inhibition of POA/BF neurons could be directly tested (1) by determining if IL-1 perfusion into $\mathrm{POA} / \mathrm{BF}$ increases extracellular adenosine levels, and/or (2) by determining if IL-1-induced effects on POA/BF neuronal discharge could be attenuated by application of an adenosine $\mathrm{A}_{1}$ receptor antagonist. 


\section{A. Total neurons}

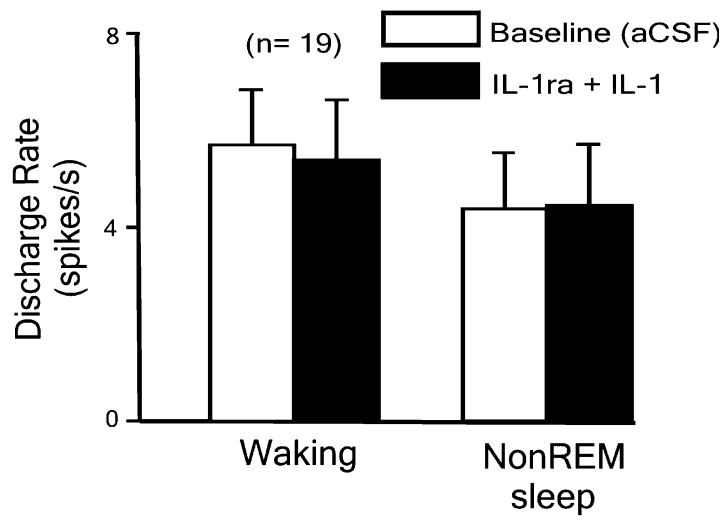

\section{B. Wake-related neurons}
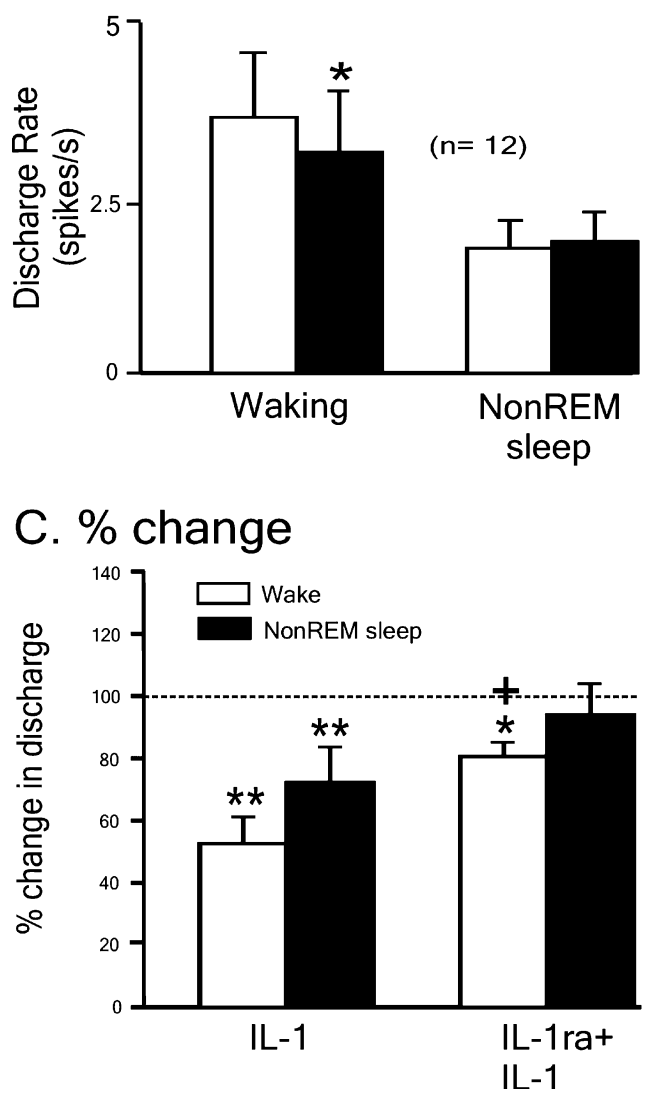

FIG. 8. Effects of IL-1 in the presence of IL-ra on the mean discharge activity of POA/BF neurons. Effects of IL-1ra + IL-1 on the mean discharge rate $( \pm$ SEM) of POA/BF neurons as a group (A) and specifically on wake-related neurons (B) during waking and nonREM sleep. In the presence of IL-ra, IL-1 produced no significant change in the discharge of $\mathrm{POA} / \mathrm{BF}$ neurons as a group, but slightly suppressed the discharge of wake-related neurons during waking. (C) Effects of IL-1 alone and IL-1 ra + IL-1 on percentage discharge of wakerelated neurons as a group during waking and nonREM sleep as compared with respective baseline values as $100 \%$. In the presence of IL-1ra, IL-1 induced suppression in the discharge was significantly attenuated. *, compared with baseline; +compared with IL-1; ${ }^{* *} P \leq 0.01 ;{ }^{*} P \leq 0.05,+P \leq 0.05$ (Wilcoxon matched-pairs signed rank and Mann-Whitney rank tests).

Although responses of sleep-related neurons were more heterogeneous than those of wake-related neurons, five of 13 sleep-related neurons exhibited increased discharge in response to IL-1. One possible explanation for the heterogeneity of response stems from the evidence that a variety of factors promote sleep within the POA/BF region (McGinty \& Szymusiak, 2003; Obal \& Krueger, 2003). Considering the multiplicity of the regulatory outputs, it is possible that subsets of sleep-related neurons have different thresholds for various neurotransmitters or neuromodulators underlying the regulation of different physiologic components within sleep. The activation of a subset of sleep-related neurons is also consistent with the hypothesis of a sleep-promoting role for IL-1. In vitro studies demonstrate the ability of IL-1 to activate POA neurons (Nakashima et al., 1989; Xin \& Blatteis, 1992; Hori \& Katafuchi, 1998), and to increase intracellular $\mathrm{Ca}^{2+}$ in cultured hypothalamic GABAergic neurons (De et al., 2002). Immunohistochemical studies from our laboratory suggest that the majority of sleep-related neurons in the POA subregion are GABAergic (Gong et al., 2004). Therefore, we hypothesize that some of the sleep-related neurons directly activated by IL-1 are GABAergic. It is also possible that the increased discharge of sleep-related neurons is due to a reduction of inhibitory influences of sleep-related neuronal synapses originating on wake-related neurons.

In summary, the data presented here demonstrate that IL-1 modulates the discharge activity of various POA/BF neurons in a manner that may induce spontaneous nonREM sleep. Our results also demonstrate that the predominant effect of IL-1 is inhibition of wakerelated neuronal activity and that the modulatory effect of IL-1 on $\mathrm{POA} / \mathrm{BF}$ neurons is mediated via IL-1 receptors.

\section{Acknowledgements}

We thank Ms Darya Stewart for her excellent technical assistance with these studies. This work was supported by grants from the National Institute of Health, MH61354 (M.N.A.), MH47480 (D.M.), HL60296 (D.M.), MH64843 (M.R.O.) and MH63323 (R.S.).

\section{Abbreviations}

$\mathrm{BF}$, basal forebrain; ICV, intracerebroventricular; IL-1, interleukin-1 $\beta$; nonREM, nonrapid eye movement; POA, preoptic area.

\section{References}

Alam, M.N. \& Mallick, B.N. (1990) Differential acute influence of medial and lateral preoptic areas on sleep-wakefulness in freely moving rats. Brain Res., 525, 242-248.

Alam, M.N., McGinty, D. \& Szymusiak, R. (1995) Neuronal discharge of preoptic/anterior hypothalamic thermosensitive neurons: relation to NREM sleep. Am. J. Physiol., 269, R1240-R1249.

Alam, M.N., Szymusiak, R., Gong, H., King, J. \& McGinty, D. (1999) Adenosinergic modulation of rat basal forebrain neurons during sleep and waking: neuronal recording with microdialysis. J. Physiol., 521, 679-690.

Baker, S.S., Stewart, D.R., Xu, F., Szymusiak, R., Opp, M.R. \& McGinty, D.F. (2003) Interleukin-1b treatment increases c-Fos protein expression in sleep active regions of the preoptic hypothalamus in rats. Neurosci. Abstract, 617.614 .

Borsody, M.K. \& Weiss, J.M. (2002) Alteration of locus coeruleus neuronal activity by interleukin-1 and the involvement of endogenous corticotropinreleasing hormone. Neuroimmunomodulation, 10, 101-121.

Cunningham, E.T. Jr, Wada, E., Carter, D.B., Tracey, D.E., Battey, J.F. \& De Souza, E.B. (1992) Distribution of type I interleukin-1 receptor messenger RNA in testis: an in situ histochemical study in the mouse. Neuroendocrinology, 56, 94-99.

De, A., Churchill, L., Obal, F. Jr, Simasko, S.M. \& Krueger, J.M. (2002) GHRH and IL1beta increase cytoplasmic $\mathrm{Ca}(2+)$ levels in cultured hypothalamic GABAergic neurons. Brain Res., 949, 209-212.

Detari, L., Rasmusson, D.D. \& Semba, K. (1999) The role of basal forebrain neurons in tonic and phasic activation of the cerebral cortex. Prog. Neurobiol., 58, 249-277. 
Dinarello, C.A. (1991) Interleukin-1 and interleukin-1 antagonism. Blood, 77, $1627-1652$.

Dinarello, C.A. (1996) Biologic basis for interleukin-1 in disease. Blood, 87, 2095-2147.

Dripps, D.J., Verderber, E., Ng, R.K., Thompson, R.C. \& Eisenberg, S.P. (1991) Interleukin-1 receptor antagonist binds to the type II interleukin-1 receptor on B cells and neutrophils. J. Biol. Chem., 266, 20311-20315.

Ericsson, A., Liu, C., Hart, R.P. \& Sawchenko, P.E. (1995) Type 1 interleukin-1 receptor in the rat brain: distribution, regulation, and relationship to sites of IL-1-induced cellular activation. J. Comp. Neurol., 361, 681-698.

Fang, J., Wang, Y. \& Krueger, J.M. (1998) Effects of interleukin-1 beta on sleep are mediated by the type I receptor. Am. J. Physiol., 274, R655-R660.

Gallis, B., Prickett, K.S., Jackson, J., Slack, J., Schooley, K., Sims, J.E. \& Dower, S.K. (1989) IL-1 induces rapid phosphorylation of the IL-1 receptor. J. Immunol., 143, 3235-3240.

Gaus, S.E., Strecker, R.E., Tate, B.A., Parker, R.A. \& Saper, C.B. (2002) Ventrolateral preoptic nucleus contains sleep-active, galaninergic neurons in multiple mammalian species. Neuroscience, 115, 285-294.

Gemma, C., Imeri, L., de Simoni, M.G. \& Mancia, M. (1997) Interleukin-1 induces changes in sleep, brain temperature, and serotonergic metabolism. Am. J. Physiol., 272, R601-R606.

Gong, H., McGinty, D., Guzman-Marin, R., Chew, K.T., Stewart, D. \& Szymusiak, R. (2004) Activation of c-fos in GABAergic neurons in the preoptic area during sleep and in response to sleep deprivation. J. Physiol. (Lond.), 556, 935-946.

Hohagen, F., Timmer, J., Weyerbrock, A., Fritsch-Montero, R., Ganter, U., Krieger, S., Berger, M. \& Bauer, J. (1993) Cytokine production during sleep and wakefulness and its relationship to cortisol in healthy humans. Neuropsychobiology, 28, 9-16.

Hori, T. \& Katafuchi, T. (1998) Cell biology and the functions of thermosensitive neurons in the brain. Prog. Brain Res., 115, 9-23.

Imeri, L., Gemma, C., De Simoni, M.G., Opp, M.R. \& Mancia, M. (1999) Hypothalamic serotonergic activity correlates better with brain temperature than with sleep-wake cycle and muscle tone in rats. Neuroscience, 89, $1241-1246$.

Jones, B.E. (2004) Activity, modulation and role of basal forebrain cholinergic neurons innervating the cerebral cortex. Prog. Brain Res., 145, 157-169.

Konsman, J.P., Parnet, P. \& Dantzer, R. (2002) Cytokine-induced sickness behaviour: mechanisms and implications. Trends Neurosci., 25, 154-159.

Krueger, J.M., Walter, J., Dinarello, C.A., Wolff, S.M. \& Chedid, L. (1984) Sleep-promoting effects of endogenous pyrogen (interleukin-1). Am. J. Physiol., 246, R994-R999.

Lu, J., Greco, M.A., Shiromani, P. \& Saper, C.B. (2000) Effect of lesions of the ventrolateral preoptic nucleus on NREM and REM sleep. J. Neurosci., 20, 3830-3842.

Lue, F.A., Bail, M., Jephthah-Ochola, J., Carayanniotis, K., Gorczynski, R. \& Moldofsky, H. (1988) Sleep and cerebrospinal fluid interleukin-1-like activity in the cat. Int. J. Neurosci., 42, 179-183.

Luk, W.P., Zhang, Y., White, T.D., Lue, F.A., Wu, C., Jiang, C.G., Zhang, L. \& Moldofsky, H. (1999) Adenosine: a mediator of interleukin-1beta-induced hippocampal synaptic inhibition. J. Neurosci., 19, 4238-4244.

Manfridi, A., Brambilla, D., Bianchi, S., Mariotti, M., Opp, M.R. \& Imeri, L. (2003) Interleukin-1beta enhances non-rapid eye movement sleep when microinjected into the dorsal raphe nucleus and inhibits serotonergic neurons in vitro. Eur. J. Neurosci., 18, 1041-1049.

McGinty, D. \& Szymusiak, R. (2003) Hypothalamic regulation of sleep and arousal. Front. Biosci., 8, 1074-1083.

McGinty, D., Szymusiak, R. \& Thomson, D. (1994) Preoptic/anterior hypothalamic warming increases EEG delta frequency activity within nonrapid eye movement sleep. Brain Res., 667, 273-277.

Muller, C.E. (2001) A1 adenosine receptors and their ligands: overview and recent developments. Farmaco, 56, 77-80.

Nakashima, T., Hori, T., Mori, T., Kuriyama, K. \& Mizuno, K. (1989) Recombinant human interleukin-1 beta alters the activity of preoptic thermosensitive neurons in vitro. Brain Res. Bull., 23, 209-213.

Obal, F. Jr \& Krueger, J.M. (2003) Biochemical regulation of non-rapid-eyemovement sleep. Front. Biosci., 8, 520-550.

Obal, F. Jr, Opp, M., Cady, A.B., Johannsen, L., Postlethwaite, A.E., Poppleton, H.M., Seyer, J.M. \& Krueger, J.M. (1990) Interleukin 1 alpha and an interleukin 1 beta fragment are somnogenic. Am. J. Physiol., 259, R439-R446.

Oka, T., Oka, K., Hosoi, M., Aou, S. \& Hori, T. (1995) The opposing effects of interleukin-1 beta microinjected into the preoptic hypothalamus and the ventromedial hypothalamus on nociceptive behavior in rats. Brain Res., 700, 271-278.

Opp, M.R. \& Krueger, J.M. (1991) Interleukin 1-receptor antagonist blocks interleukin 1-induced sleep and fever. Am. J. Physiol., 260, R453R457.

Opp, M.R. \& Krueger, J.M. (1994) Anti-interleukin-1 beta reduces sleep and sleep rebound after sleep deprivation in rats. Am. J. Physiol., 266, R688R695.

Opp, M.R., Obal, F. Jr \& Krueger, J.M. (1988) Effects of alpha-MSH on sleep, behavior, and brain temperature: interactions with IL 1. Am. J. Physiol., 255, R914-R922.

Opp, M., Obal, F. Jr \& Krueger, J.M. (1989) Corticotropin-releasing factor attenuates interleukin 1-induced sleep and fever in rabbits. Am. J. Physiol., 257, R528-R535.

Opp, M.R., Obal, F. Jr \& Krueger, J.M. (1991) Interleukin 1 alters rat sleep: temporal and dose-related effects. Am. J. Physiol., 260, R52-R58.

Paxinos, G. \& Watson, C. (1998) The Rat Brain: in Stereotaxic Coordinates. Academic Press, New York.

Porkka-Heiskanen, T., Alanko, L., Kalinchuk, A. \& Stenberg, D. (2002) Adenosine and sleep. Sleep Med. Rev., 6, 321-332.

Rasmusson, D.D., Clow, K. \& Szerb, J.C. (1994) Modification of neocortical acetylcholine release and electroencephalogram desynchronization due to brainstem stimulation by drugs applied to the basal forebrain. Neuroscience, 60, 665-677.

Ribeiro, J.A. (1999) Adenosine A2A receptor interactions with receptors for other neurotransmitters and neuromodulators. Eur. J. Pharmacol., 375, $101-113$.

Rosenwasser, L.J. (1998) Biologic activities of IL-1 and its role in human disease. J. Allergy. Clin. Immunol., 102, 344-350.

Rothwell, N.J. \& Luheshi, G.N. (2000) Interleukin 1 in the brain: biology, pathology and therapeutic target. Trends Neurosci., 23, 618-625.

Saper, C.B., Chou, T.C. \& Scammell, T.E. (2001) The sleep switch: hypothalamic control of sleep and wakefulness. Trends Neurosci., 24, 726-731.

Schobitz, B., De Kloet, E.R. \& Holsboer, F. (1994) Gene expression and function of interleukin 1, interleukin 6 and tumor necrosis factor in the brain. Prog. Neurobiol., 44, 397-432.

Semba, K. (2004) Phylogenetic and ontogenetic aspects of the basal forebrain cholinergic neurons and their innervation of the cerebral cortex. Prog. Brain Res., 145, 3-43.

Sherin, J.E., Shiromani, P.J., McCarley, R.W. \& Saper, C.B. (1996) Activation of ventrolateral preoptic neurons during sleep. Science, 271, 216-219.

Shirakawa, F., Chedid, M., Suttles, J., Pollok, B.A. \& Mizel, S.B. (1989) Interleukin 1 and cyclic AMP induce kappa immunoglobulin light-chain expression via activation of an NF-kappa B-like DNA-binding protein. Mol. Cell. Biol., 9, 959-964.

Stylianou, E., O’Neill, L.A., Rawlinson, L., Edbrooke, M.R., Woo, P. \& Saklatvala, J. (1992) Interleukin 1 induces NF-kappa B through its type I but not its type II receptor in lymphocytes. J. Biol. Chem., 267, 1583615841 .

Szymusiak, R., Alam, N. \& McGinty, D. (2000) Discharge patterns of neurons in cholinergic regions of the basal forebrain during waking and sleep. Behav. Brain. Res., 115, 171-182.

Szymusiak, R., Alam, N., Steininger, T.L. \& McGinty, D. (1998) Sleep-waking discharge patterns of ventrolateral preoptic/anterior hypothalamic neurons in rats. Brain Res., 803, 178-188.

Takahashi, S., Kapas, L., Fang, J., Seyer, J.M., Wang, Y. \& Krueger, J.M. (1996) An interleukin-1 receptor fragment inhibits spontaneous sleep and muramyl dipeptide-induced sleep in rabbits. Am. J. Physiol., 271, R101R108.

Toth, L.A. \& Krueger, J.M. (1988) Alteration of sleep in rabbits by Staphylococcus aureus infection. Infect. Immunol., 56, 1785-1791.

Toth, L.A. \& Krueger, J.M. (1989) Effects of microbial challenge on sleep in rabbits. FASEB J., 3, 2062-2066.

Xi, X. \& Toth, L.A. (2000) Lipopolysaccharide effects on neuronal activity in rat basal forebrain and hypothalamus during sleep and waking. Am. J. Physiol., 278, R620-R627.

Xin, L. \& Blatteis, C.M. (1992) Blockade by interleukin-1 receptor antagonist of IL-1 beta-induced neuronal activity in guinea pig preoptic area slices. Brain Res., 569, 348-352.

Yabuuchi, K., Minami, M., Katsumata, S. \& Satoh, M. (1994) Localization of type I interleukin-1 receptor mRNA in the rat brain. Mol. Brain Res., 27, $27-36$. 